\title{
Neonatal yoksunluk sendromu olan prematüre bebek
}

Premature infant with neonatal abstinence syndrome

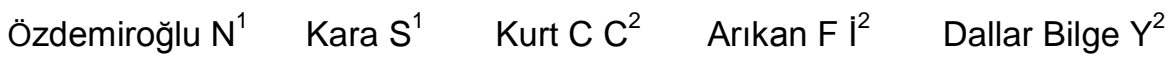

${ }^{1}$ Ankara Eğitim ve Araştırma Hastanesi, Yenidoğan Kliniği, Ankara, Türkiye

${ }^{2}$ Ankara Eğitim ve Araştırma Hastanesi, Çocuk Sağlığı ve Hastalıkları Kliniği, Ankara, Türkiye

\section{Özet}

Neonatal yoksunluk sendromu (NYS) prenatal bağımlıık yapan maddelere maruziyet sonrası çekilme semptomlarılla ve fiziksel bağımılıkla karakterize klinik bir durumdur. Opioid dışındaki tüm ilaç sınıfları için bu belirtiler genellikle kendi kendini sınırlar ve farmakolojik tedavi gerektirmez. Gelişmiş ülkelerde hamile kadınların \%4.4'ü yasadışı ilaç kullanmaktadır. Gebelik boyunca eroine maruziyet prematürite, açıklanamayan intrauterin gelişme geriliği, plasenta yetmezliği, doğum sonrası kanama, preeklampsi ve erken membran rüptürü de dahil olmak üzere fetal ölüm ve neonatal morbidite ile ilişkilidir. Ülkemizde neonatal yoksunluk sendromu ile doğan bebeklerle ilgili oldukça sınırı sayıda olgu sunumu yapılmışırı.

Anahtar Sözcükler: Prematürite, yoksunluk sendromu, eroin, kokain.

\section{Summary}

Neonatal abstinence syndrome (NYS) is a clinical condition characterized by physical dependence and withdrawal symptoms after prenatal exposure to addictive substances. These symptoms are self-limiting and usually do not require pharmacological treatment for all classes of drugs, except for opioids. In developed countries $4.4 \%$ of pregnant women use illegal drugs. Heroin exposure during pregnancy causes prematurity, unexplained intrauterine growth restriction, placental insufficiency, postpartum hemorrhage, including pre-eclampsia and premature rupture of membranes which is associated with fetal death and neonatal morbidity. In our country, there are a very limited number of case reports about babies born with neonatal abstinence syndrome.

Key Words: Prematurity, abstinence syndrome, heroin, cocaine.

\section{Giriş}

Neonatal yoksunluk sendromu (NYS) prenatal bağımlılık yapan maddelere maruziyet sonrası çekilme semptomlarılya ve fiziksel bağımlılıkla karakterize klinik bir durumdur. Opioid dışındaki tüm ilaç sınıfları için bu belirtiler genellikle kendi kendini sınırlar ve farmakolojik tedavi gerektirmez $(1,2)$. Ülkemizde gebe kadınlarda bu alanda yapıımış çalışma bulunmamaktadır. Geçmiş yıllarda eroin kadınlar arasında en yaygın kullanılan madde iken; günümüzde kokain ve diğer uyuşturucular daha yüksek oranda kullanılmaktadır (3).

\footnotetext{
Yazışma Adresi: Semra KARA

Ankara Eğitim ve Araştırma Hastanesi, Yenidoğan Kliniği, Ankara, Türkiye
}

Kronik ve aralıklı ilaç maruziyetinin fetusta ve yenidoğanda etkileri, kötü maternal beslenme, doğumdan sonra akut yoksunluk belirtileri, uzun dönem fiziksel ve nörolojik gelişim etkilenmesi şeklinde sonuçlanır. İnutero ilaç maruziyetine kalan infatlarda sıklıkla sosyal ve çevresel risk faktörleri ve maternal multipl madde alımı bulunmaktadır. Bu durum spesifik ilaç maruziyetinin etkilerinin uzun dönem nörogelişimsel sonuçlarının değerlendirilmesini zorlaştırır.

Gelişmiş ülkelerde hamile kadınların \% 4.4'ü yasadışı ilaç kullanmaktadır (4). Gebelik boyunca eroine maruziyet prematürite, açıklanamayan intrauterin gelişme geriliği, plasenta yetmezliği, doğum sonrası kanama, preeklampsi ve erken membran rüptürü de dahil olmak üzere fetal ölüm ve neonatal morbidite ile ilişkilidir $(5,6)$. 


\section{Olgu Sunumu}

36 yaşındaki annenin 3. gebeliğinden 3.yaşayan olarak 31.gestasyon haftasında $1220 \mathrm{gr} \mathrm{C} / \mathrm{S}$ ile doğan hastanın 1. dakika APGAR skoru 6,5. dakikada 7 idi. Prenatal öyküde annenin gebelik döneminde düzenli takibinin olmadığı öğrenildi. Düzenli eroin ve kokain kullandığı ve günde iki paket sigara içtiği öğrenildi. Vakanın fizik muayenesinde vücut ağırlığı $1220 \mathrm{gr}(10-25 \mathrm{P})$, boy 35 cm (<10 P), baş çevresi 27 cm (10-25 P) idi. Bebeğin ilk fizik muayenesinde patolojik özelliği yoktu. Postnatal 1. saatinde fizik muayenesinde tremor, tiz sesli ağlama, artmış tonus, irritabilite tespit edildi. NYS düşünülen hastada yapılan laboratuar tetkiklerinde tam kan sayımında beyaz küre $7.500 / \mathrm{mm}^{3}$, Htc $\% 53$, Hgb 16.4 $\mathrm{g} / \mathrm{dL}$, trombosit sayısı $97.000 / \mathrm{mm}^{3}$ olarak saptandı. Kan biyokimyasında sodyum: $140 \mathrm{mEq} / \mathrm{L}$, potasyum: 5.6 mEq/L, kalsiyum: $7.4 \mathrm{mg} / \mathrm{dL}$ ve CRP: $0.3 \mathrm{mg} / \mathrm{dl}$ idi. İlaç bağımlı anne bebeklerinde kullanılan Modifiye Finnegan Skorlamasına göre bebek değerlendirildiğinde postnatal 2. saatinde skoru 7 puan ve 6 . saat tekrar değerlendirilen bebekte skor 9 puan olarak belirlendi (Tablo-1).

Tablo-1. Modifiye Finnegan Neonatal Yoksunluk Sendromu Skorlaması (7).

\begin{tabular}{|c|c|}
\hline Merkezi Sinir Sistemi Bulguları & \\
\hline Yüksek sesli ağlama & 2 \\
\hline Devamlı yüksek sesli ağlama & 3 \\
\hline Beslenme sonrası uyku $<1$ saat & 3 \\
\hline Beslenme sonrası uyku $<2$ saat & 2 \\
\hline Beslenme sonrası uyku $<3$ saat & 1 \\
\hline Uyarı ile hafif tremor & 1 \\
\hline Uyarı ile orta ve ciddi tremor & 2 \\
\hline Uyarısız hafif tremor & 3 \\
\hline Uyarısız orta ve ciddi tremor & 4 \\
\hline Artmış kas tonusu & 2 \\
\hline Deride soyulma & 1 \\
\hline Myoklonik atım & 3 \\
\hline Generalize konvülsiyon & 5 \\
\hline \multicolumn{2}{|c|}{ Metabolik, vazomotor, solunumsal bulgular } \\
\hline Terleme & 1 \\
\hline Ateş $\left(37,5-38,3 C^{\circ}\right)$ & 1 \\
\hline Ateş $\left(>38,4 \mathrm{C}^{\circ}\right)$ & 2 \\
\hline Sık esneme ( >3-4 ) & 1 \\
\hline Burun tıkanıklığı & 1 \\
\hline Hapşırma ( >3-4 ) & 1 \\
\hline Nazal akıntı & 2 \\
\hline Solunum hızı $>60 / d k$ & 1 \\
\hline Solunum hızı >60/dk ve retraksiyonlar & 2 \\
\hline \multicolumn{2}{|l|}{ Gastrointestinal bulgular } \\
\hline Artmış emme & 1 \\
\hline Kötü beslenme & 2 \\
\hline regürjitasyon & 2 \\
\hline Projektil kusma & 3 \\
\hline Dışkı kaçırma & 2 \\
\hline Sulu dışkılama & 3 \\
\hline
\end{tabular}

Hiperirritabilite bulgularının tedavisi için fenobarbital 20 $\mathrm{mg} / \mathrm{kg}$ yükleme dozu şeklinde başlandı. İdame tedavide $5 \mathrm{mg} / \mathrm{kg}$ 'dan günde 2 dozda başlandı. Hasta ışıksız ve sessiz bir ortama alınarak tedavi ve takibine devam edildi. 24 saat sonra bulgularında gerileme olan hastanın Finnegan Skorlaması 6 puan hesaplandı. Bebeğe NYS tanısı kondu. Hastamızın Yenidoğan Yoğun Bakım ünitesinde gözlem sürecinde prematürite sorunlarının yanı sıra NYS semptomları açısından takip edilen hastanın semptomlarının azalması üzerine 2. haftada fenobarbital dozu $3 \mathrm{mg} / \mathrm{kg} / \mathrm{doz}$ olarak azaltıldı. Takibinin 3.haftasında hastanın Finnegan Skorlaması 0 saptanması üzerine fenobarbital tedavisi kesildi.

\section{Tartışma}

Madde bağımlılığı olan annelerin bebeklerinde yoksunluğa bağlı en sık sinir sistemi, gastroinstestinal sistem ve solunum sistemlerinin etkilendiği bildirilmiştir $(3,8)$. NYS klinik bulguları ile benzerlik gösteren hipokalsemi, hipoglisemi, enfeksiyon hipertiroidizm, hipomagnezemi ve travma (santral sinir sistemi kanamaları, anoksik beyin hasarı) gibi durumlar ayırıcı tanıda düşünülmelidir (9).

Klinik bulgular \%50-75 infantta ilk 48 saatte meydana gelir. Bu süre annenin günlük aldığı doz (günlük 6 mg'dan az alınan dozlarda bebek asemptomatik veya hafif şiddette semptom söz konusudur), bağımlılığın süresi (bir yıldan uzun süre bağımlılığı olan anne bebeklerinde $>\% 70$ oranında yoksunluk sendromu görülür) ve annenin son aldığı dozun süresi (son 24 saat içerisinde annenin son dozu almış olması insidansı arttırır) ile ilişkilidir (10).

NYS'de sinir sistemi bulguları; tremor, irritabilite, uyanıklık süresinin artması, yüksek sesle ağlama, hipertonisite, hiperaktif refleksler, konvülziyon, esneme, hapşırma gibi non-spesifik bulguları içerir. Vakamızda sinir sitemi bulgularından tiz sesle, ağlama, tremor, artmış irritabilite ve esneme mevcuttu. Opioid yoksunluk sendromuna sahip bebeklerin \%2-11'inde konvülziyonlar görülebilir. Konvülziyon, tremor ve hiperirritabilite en sık saptanan bulgulardır. Tremorlar daha çok ince ve jitterness özelliğindedir. Vakamızda jitterness özelliğindeydi. Yenidoğandaki nöbetlerden farklı olarak NYS'de görülen konvülziyonlarda istemdışı göz hareketleri, bakışın sabitleşmesi ve kol-bacaklarda titreme olmaz. Kol ve bacaklarda genellikle daha abartılı ve kaba hareketler göze çarpar. Kolların hareketi kanat çırpmayı andırır (11,12-14). Ek olarak NYS'li bebeklerin \%30'unda anormal EEG bulguları gözlenmiştir (15).

Merkezi sinir sistemi bulgularını en sık gastrointestinal sistem bulguları izler. Gastrointestinal sisteme ait bulgular: artmış emme, kötü beslenme, sulu dışkılama, kusma veya regürjitasyon gibi bulgular ile karşımıza çıkabilir (12-14). Bunlardan en önemlisi beslenme yetersizliğidir. Bebekte engellenemeyen bir emme 
hareketi vardır (16). Terleme, burun tıkanıklığı, nazal akıntı, unstabil vücut sıcaklığı, takipne gibi bulgular metabolik ve otonom sinir sisteminin etkilenmesine bağlı olarak gözlenebilir. Vakamızda bu semptomlardan takipne ve emme hareketi vardı.

NYS'li <35 haftadan küçük prematüre infantlarda opioid yoksunluk semptomlarının görülmesi riski term infantlara göre daha düşüktür. Bu risk gestasyonel yaşın azalması ile düşer.

Prematürelerde santral sinir sisteminin immatür gelişimi, intrauterin madde maruziyeti periyodunun daha kısa olması, madde depolanması için yağ dokusunun düşük olması, yoksunluk semptomlarının prematürelerde terme bebeklere göre değerlendirilme güçlüğü bu durum için olası nedenler olarak gösterilmiştir (8).

Prematür olan olgumuzda fizik muayenede tremor, myoklonik atım, aşırı emme isteği, sürekli esneme, ajitasyon, irritabilite gibi merkezi sinir sistemi bulguları tespit edildi.

Yenidoğanda opioid tespiti için idrar, kan, mekonyum incelemesi ve saç analizi gibi çeşitli testler kullanılabilir. Opioidler intrauterin hızla metabolize olmaları nedeniyle yenidoğan idrar ve kanında tespitleri zordur. Yanlış negatif sonuç oranı yüksek olması nedeniyle sensitiviteleri düşüktür $(8,17)$. Benzer şekilde saçta neonatal saç incelemesi de yanıltıcı olabilir. En iyi tanı testi mekonyum incelemesidir. Spesifitesi \%94.6 olarak bildirilmiştir (18). Ülkemizde mekonyum ve saç incelemesinin rutin laboratuvarlarda yapılmaması nedeniyle hastamızda bu iki yöntem ile analiz yapılamadı. Pratik uygulamada anamnez, klinik bulgular ve skorlama sistemi tanı ve tedaviye başlamak için daha çok dikkate alınmaktadır (19). NYS'de farmakoterapi, ateş, azalmış uyku süresi ve kilo kaybı ya da kusma nedeniyle dehidratasyon, ishal veya kötü beslenme gibi yoksunluk semptomlarının varlığında endikedir (20). Bu nedenle yoksunluk sendromunun derecesini belirlemek için düzenli aralıklarla hastaya skorlama uygulanmalıdır. Biz hastamızda mevcut skorlama yöntemlerinden Finnegan Skorlama Sistemini (21) kullandık. Tedavide dış uyarılar minimuma indirilmeli ve bebek sakin, sessiz ve ışıksız bir ortama alınmalıdır. Tedavide birçok farmakolojik ajan kullanılmaktadır. Opioidle ilişkili NYS için morfin, metadon ve buprenorfine tedavi seçenekleri arasındadır. Fenobarbital klonidin ve diazepam çoklu ilaç yoksunluğunda kullanılırken opioid yoksunluğunda da ek olarak kullanılabilir (17). Olgumuzda Finnegan skorunun çok yüksek olmaması nedeniyle sadece Fenobarbital başlandı ve olgu sessiz, sakin ve ışıksız bir ortamda izlendi.

İntrauterin eroin maruziyeti olan bebeklerde mortalite ek başına yoksunluk semptomları nedeniyle değil komplikasyonları olan prematürite, enfeksiyon ve perinatal asfiksi nedeniyle olmaktadır (22).

Sonuç olarak, ülkemizde NYS ile doğan bebeklerle ilgili sınırı sayıda çalışmada olgu sunumu yapılmıştır (23). Biz de bu nedenle bu prematür NYS olan hastamızı sunmayı istedik.

\section{Kaynaklar}

1. Schneck H. Narcotic withdrawal symptoms in the newborn infant resulting from maternal addiction. J Pediatr 1958;52(5):584-7.

2. Dikshit S.K. Narcotic withdrawal syndrome in newborns. Indian J Pediatr 1961;28(1):11-5.

3. Sherwood RA, Keating J, Kavvadia V, Greenough A, Peters TJ. Substance misuse in early pregnancy and relationship to fetal outcome. Eur J Pediatr 1999;158(6):488-92.

4. Merikangas KR, McClair VL. Epidemiology of substance use disorders. Hum Genet 2012;131(6):779-89.

5. Finnegan LP, Kandall SR, In Lowinson JH, Ruiz P, Millman RB. (eds): Maternal and Neonatal Effects of Alcohol and Drugs. Philadelphia: Lippincott Williams \& Wilkins; 2005:805-39.

6. Kennare R, Heard A, Chan A. Substance use during pregnancy: Risk factors and obstetric and perinatal outcomes in South Australia. Aust N Z J Obstet Gynaecol 2005;45(3):220-5.

7. Behnke M, Eyler FD. The consequences of prenatal substance use for the developing fetus, newborn and young child. Int $J$ Addict 1993;28(13):1341-91.

8. Hudak ML, Tan RC, Committee on Drugs, et al. Neonatal drug withdrawal. Pediatrics 2012;129(2):e540-60.

9. Schuckit MA. Opioid druge abuse and dependence. In: Fauci AS, Braunwald E, Kasper DL, Hauser SL, Longo DL, Jameson JL, Loscalzo J (eds). Harrison's Principles of Internal Medicine.17th ed, McGraw-Hill: New York; 2008:388-402.

10. Waldemar AC. Substance abuse and neonatal abstinence. In: Kliegman RM, Behrman RE, Jenson HB, Stanton BF (eds). Nelson Textbook Pediatrics. Philadelphia: Saunders Elsevier; 2012:623-5.

11. Kuschel C. Managing drug withdrawal in the newborn infant. Semin Fetal Neonatal Med 2007;12(2):127-33.

12. Zelson C, Rubio E, Wassermann E. Neonatal narcotic addiction: 10 year observation. Pediatrics 1971; 48(2):178-89.

13. Kandall SR, Gartner LM. Late presentation of drug withdrawal symptoms in newborns. Am J Dis Child 1974;127(1):58-61.

14. Herzlinger RA, Kandall SR, Vaughan HG Jr. Neonatal seizures associated with narcotic withdrawal. J Pediatr 1977;91(4):63841.

15. Van Baar AL, Fleury P, Soepatmi S, Ultee CA, Wesselman PJ. Neonatal behavior after drug dependent pregnancy. Arch Dis Child 1989;64(2):235-40.

16. Abdel-Latif ME, Pinner J, Clews S,Cooke F, Lui K, Oei J. Effects of breast milk on the severity and outcome of neonatal abstinence syndrome among infants of drug-dependent mothers. Pediatrics 2006;117(6):1163-9. 
17. Bio LL, Siu A, Poon CY. Update on the pharmacologic management of neonatal abstinence syndrome. J Perinatol 2011;31(11):692-701.

18. Hunt RW, Tzioumi D, Collins E, Jeffery HE. Adverse neurodevelopmental outcome of infants exposed to opiate in-utero. Early Hum Dev 2008;84(1):29-35.

19. Can E, Bülbül A,Uslu S, Güran Ö, Nuhoğlu A. Neonatal yoksunluk sendromu. Şişli Etfal Hastanesi Tıp Bülteni 2010;44(2):124-1.

20. AAP Committee on Drugs. Neonatal drug withdrawal. Pediatr 1998;101(6):1079-88.

21. Finnegan LP, Kron RE, Connaughton JF, Emich JP. Assessment and treatment of abstinence in the infant of the drugdependent mother. Int J Clin Pharmacol Biopharm 1975;12(1-2):19-32.

22. Sinha C, Ohadike P, Carrick P, Pairaudeau P, Armstrong D, Lindow SW. Neonatal outcome following maternal opiate use in late pregnancy. Int J Obstet Gynaecol 2001;74(3):241-6. 